\title{
Growth in non-anemic infants supplemented with different prophylactic iron doses
}

\author{
Danielle G. da Silva, ${ }^{1}$ Sylvia do C. C. Franceschini, ${ }^{2}$ Dirce M. Sigulem ${ }^{3}$
}

\begin{abstract}
Objective: To compare the effects of different prophylactic iron doses on the growth and nutritional status of non-anemic infants.

Methods: Prospective randomized study. Infants aged 5.0 to 6.9 months who met the inclusion criteria and showed capillary hemoglobin $\geq 11 \mathrm{~g} / \mathrm{dL}$ were randomly allocated into three groups who received the following prophylactic doses of iron supplement (ferrous sulfate): $1 \mathrm{mg} / \mathrm{kg} /$ day $(\mathrm{n}=39) ; 2 \mathrm{mg} / \mathrm{kg} /$ day $(\mathrm{n}=36) ;$ and $25 \mathrm{mg} /$ week $(\mathrm{n}=39)$. This supplementation was given during 16 weeks. Both weight and length were measured. The nutritional status was evaluated by comparing z scores for weight/age, length/age and weight/length based on the World Health Organization (2006) references. Morbidity information was collected during monthly visits.

Results: The groups showed similar nutritional status before supplementation. There were no differences in daily nutrient intake among groups. During the study, weight and length gain, and increments in anthropometric indices did not differ statistically among supplemented groups. The occurrence and duration of morbidity episodes did not differ statistically among groups. In general, improvements were observed in both weight/age and weight/length indices in the population under study, whereas length/age showed no differences before and after supplementation.
\end{abstract}

Conclusion: Different prophylactic iron doses had no different effects on the growth and nutritional status of non-anemic infants.

J Pediatr (Rio J). 2008;84(4):365-372: Growth, iron, administration and dosage, infant, iron deficiency anemia, morbidity.

\section{Introduction}

Iron deficiency anemia is a highly prevalent nutritional disorder in many populations worldwide. Children in the first 2 years of life are considered risk groups. ${ }^{1}$ The main consequences of childhood anemia are the probably irreversible deficits in mental and psychomotor development. ${ }^{2}$ However, other effects are also mentioned, such as behavioral changes, ${ }^{2}$ decreased resistance to infections, ${ }^{3}$ and reduced growth processes. ${ }^{4}$

Iron supplementation is an essential strategy for anemia prevention in areas where its prevalence is high. ${ }^{5}$ In the literature, several prophylactic iron supplementation regimes have been proposed to prevent anemia in the first years of

1. Mestre. Doutoranda, Programa de Pós-Graduação em Nutrição, Universidade Federal de São Paulo - Escola Paulista de Medicina (UNIFESP-EPM), São Paulo, SP, Brazil.

2. Doutora. Docente, Programa de Pós-Graduação em Ciência da Nutrição, Departamento de Nutrição e Saúde, Universidade Federal de Viçosa (UFV), Viçosa, MG, Brazil.

3. Doutora. Docente, Programa de Pós-Graduação em Nutrição, UNIFESP-EPM, São Paulo, SP, Brazil.

Financial support: Fundação de Amparo à Pesquisa do Estado de São Paulo (FAPESP) e Coordenação de Aperfeiçoamento de Pessoal de Nível Superior (CAPES).

No conflicts of interest declared concerning the publication of this article.

Suggested citation: da Silva DG, Franceschini SC, Sigulem DM. Growth in non-anemic infants supplemented with different prophylactic iron doses. J Pediatr (Rio J). 2008;84(4):365-372.

Manuscript received Jul 16 2007, accepted for publication Sep 052008.

doi:10.2223/JPED.1817 
life, such as those by the World Health Organization, ${ }^{1}$ Pediatric committees, ${ }^{6,7}$ and by specific federal departments, such as the Brazilian Ministry of Health. ${ }^{8}$ The real advantages and disadvantages of using these different prophylactic iron supplementation regimes have been poorly investigated. In addition, there is a paucity of studies on the effect of these regimes on specific groups such as non-anemic or non-iron-deficient infants. Iron is essential to many biochemical processes, such as electron transfer reactions, and regulation of cell growth and differentiation. On the other hand, it is also a potent cellular pro-oxidant, and its excess may impair many cellular processes. ${ }^{9}$ There is controversy over whether iron supplementation affects infants' growth. Studies have yielded different results, ranging from absence of effects ${ }^{10,11}$ to advantages ${ }^{12,13}$ and disadvantages. ${ }^{14,15}$ The possible effect of iron supplementation on growth can be caused by alterations in the immune system, which result in high or low morbidity risk. However, there is no consensus on the association between iron supplementation and the incidence of morbidity among children. ${ }^{3,16,17}$

It has been argued that anemic children seem to respond more positively to iron supplementation. Nevertheless, the effects of iron supplementation on the growth of non-anemic or non-iron-deficient children remain inconclusive. ${ }^{18}$ The risks and benefits of iron supplementation apparently vary according to initial hemoglobin levels and to iron nutritional status markers. The beneficial effects of iron supplementation have been shown primarily in anemic children. ${ }^{9}$

It is known that universal supplementation with prophylactic iron doses can reach a great number of non-anemic infants. However, its effects on growth are still controversial. Therefore, the purpose of this study was to compare the effects of different prophylactic iron doses (administered on a daily or weekly basis) on the growth and nutritional status of non-anemic infants.

\section{Methods}

This a prospective, randomized study of prophylactic intervention, developed with infants who live in Viçosa (State of Minas Gerais, in the southeast of Brazil). Data collection took place between April, 2005 and October, 2006.

Data from the Statement of Live Birth Form were used for participants' identification. For investigation of inclusion criteria, children born in Viçosa were visited between October 2004 and November, 2005. Parents who showed interest in participating in the study were interviewed. Inclusion criteria were: (1) age 5.0 to 6.9 months; (2) infants living in the urban area; (3) full-term, single-birth babies; (4) birth weight $\geq$ $2,500 \mathrm{~g}$; (5) mother's age $>19$ years; 6 ) absence of neonatal intercurrent events, of congenital anomalies and of chronic diseases; (7) no previous iron supplementation; (8) non-exclusive breastfeeding; and (9) capillary hemoglobin $\geq$ $11 \mathrm{~g} / \mathrm{dL}$ (non-anemic infants).
In the screening phase, the capillary hemoglobin of 213 infants who met the first eight criteria of inclusion was measured. The 78 infants diagnosed with anemia (hemoglobin < $11 \mathrm{~g} / \mathrm{dL}$ ) (36.6\%) were referred for treatment and excluded from the study, whereas 135 non-anemic infants (hemoglobin $\geq 11 \mathrm{~g} / \mathrm{dL})(63.4 \%)$ were randomly included in the three groups of prophylactic intervention with iron supplements.

Group I ( $n=51$ ) received $1 \mathrm{mg}$ of elemental iron $/ \mathrm{kg} / \mathrm{day}$, as recommended by the American Academy of Pediatrics ${ }^{6}$ and the Brazilian Society of Pediatrics. Group II $(n=42)$ received $2 \mathrm{mg} / \mathrm{kg} / \mathrm{day}$, as recommended by the World Health Organization. ${ }^{1}$ Group III $(\mathrm{n}=42)$ received $25 \mathrm{mg} /$ week, as recommended by the Brazilian Ministry of Health. ${ }^{8}$ Supplementation was carried out during 16 weeks.

Sample size was calculated in order to meet the main goal of the study (comparison of blood levels) and not the goal presented in this paper.

Liquid ferrous sulfate, containing $25 \mathrm{mg}$ of elemental iron by $\mathrm{mL}$ of product, was administered. Participants' parents were given the supplements for free, and were told how to administer them. The supplement should be given 1 hour prior to lunch. Supplementation was monitored through four monthly home visits. Based on the "intention-to-treat" principle, all participants were included in the analysis, regardless of their compliance.

For inclusion in the study, a questionnaire containing information about the infant (birth conditions, socioeconomic background and breastfeeding history) was answered by parents. Exclusive breastfeeding time was defined as the age (in days) during which the infant ingested only breast milk, without water or tea. Predominant breastfeeding time was defined as the age during which the infant was predominantly fed breast milk, but was also given water, teas or fruit juice. ${ }^{19}$

During the intervention period, food intake was evaluated by means of the 24-hour recall method, applied in the second and fourth months of supplementation. The means of both evaluations were calculated. The amount of breast milk intake was calculated through the formula proposed by Drewett et al., ${ }^{20}$ which estimates the milk volume based on the number of breastfeedings per day and on infant's age. The Dietpro software was used to calculate the amount of nutrients. Bioavailable iron was calculated according to Monsen et al. $^{21}$

Weight and height were measured at the beginning and at the end of the supplementation period. An electronic scale with capacity for $15 \mathrm{~kg}$ and accuracy of $15 \mathrm{~g}$ was used to measure weight. A 1.5-meter long horizontal rod with 0.1 -centimeter subdivisions was used to measure length. The nutritional status was evaluated by using the $z$ scores of weight/age, length/age and weight/length, based on the 
World Health Organization recommendations (2006). ${ }^{22}$ Nutritional status was calculated by using WHO Antho 2005 software, beta 2006 version.

Morbidity data were obtained during four monthly home visits by means of parental interviews. Morbidity in the past 15 days was investigated, as well as the duration of diarrhea, fever, cough, nasal congestion and coryza, or wheezing. Diarrhea was defined based on the presence of three or more evacuations of mushy stools a day. Fever was identified based on mother's perception of an increase in her infant's temperature. Coughing, coryza, nasal congestion and wheezing were questioned because these are symptoms that indicate respiratory infections.

Capillary blood samples were collected by heel prick during the screening phase of the study for hemoglobin measurement. The blood was collected in a microcuvette, using a portable HemoCue photometer for hemoglobin measurement. A cutoff point of $11 \mathrm{~g} / \mathrm{dL}$ was adopted for the diagnosis of anemia. ${ }^{1}$ By the end of the study, samples of venous blood were collected in a municipal laboratory of clinical analysis for evaluation of laboratory iron parameters (data not shown).

All the information obtained during the home visits, including anthropometric measurements, was collected by the researcher in charge of the study, helped by properly trained Nutrition undergraduates. Participants' parents signed a free informed consent form. The procedures adopted in the study were approved by the Research Ethics Committee of Universidade Federal de São Paulo and Universidade Federal de Viçosa.

The statistical analyses were done in SPSS for Windows, version 10.0.1. The chi-square test or Fisher's exact test was used for comparison of proportions. The paired ${ }^{t}$ test was used for comparison of anthropometric data before and after supplementation. Parametric continuous variables were compared between groups by the analysis of variance and Bonferroni multiple comparison test. The Kruskal-Wallis test was used to compare the groups of non-parametric continuous variables. The statistical significance was set at $5 \%$ or $p<$ 0.05 .

\section{Results}

One hundred and thirty-five infants were included in the study ( $n=51$ in group $I, n=42$ in group II and $n=42$ in group III). Of these, 114 completed the intervention and 21 were lost to follow-up. The reasons for these losses were: patient withdrawal ( $n=7)$; supplement intolerance $(n=6)$; non-compliance, that is, the supplement was not supplied until the first visit after its use was recommended $(n=4)$; moving out of town ( $n=2)$; and anemia diagnosed during the study by an exam requested by physicians $(n=2)$. The sample loss did not differ statistically between the studied groups ( $\mathrm{n}$ $=12$ in group I, $\mathrm{n}=6$ in group II and $\mathrm{n}=3$ in group III) ( $\mathrm{p}=$ 0.091).
The characteristics evaluated at admission did not differ between the supplemented groups. Besides, there were no statistical differences in daily intake of energy and nutrients during the supplementation period (Table 1).

Before supplementation, nutritional deficits ( $<-2$ z score) in the total population were $4.4 \%(n=5)$ for weight/age, $2.6 \%$ $(n=3)$ for length/age and 5.3\% $(n=6)$ for weight/length. By the end of the supplementation, the population presented deficits of $2.6 \%(n=3)$ in weight/age, $3.5 \%(n=4)$ in length/ age and $3.5 \%(n=4)$ in weight/length. When the mean anthropometric measurements were compared before and after supplementation, there was a significant increase in weight/age (initial mean $=0.06 \pm 1.07$ versus final mean $=$ $0.15 \pm 1.15 ; \mathrm{p}=0.029$ ) and in weight/length (initial mean $=$ $0.05 \pm 1.08$ versus final mean $=0.18 \pm 1.15 ; p=0.017$ ), but no statistically significant change in length/age was observed (initial mean $=0.15 \pm 1.07$ versus final mean $=0.11 \pm 1.09 ; \mathrm{p}$ $=0.297$ ).

Initial values of weight, length and of weight/age, length/ age and weight/length did not differ statistically between groups. After supplementation, groups I, II and III gained $1.20,1.26$ and $1.37 \mathrm{~kg}$ in weight and $5.15,5.22$ and $5.61 \mathrm{~cm}$ in length, respectively (values of $p>0.05$ ). In the evaluated groups, final means of anthropometric indices did not differ from the initial ones, except for weight/age in group III and weight/length in group II, which showed a significant increase. During the study period, weight gain, length gain and increases in anthropometric indices did not differ statistically between groups (Table 2).

Supplemented groups did not differ as to the occurrence of morbidity during the four monthly home visits. Besides, no statistically significant differences were found among groups concerning the occurrence and duration of diarrhea, fever and symptoms of respiratory diseases, such as cough, coryza, nasal congestion and wheezing (Table 3 ).

\section{Discussion}

In the present study, the groups of non-anemic infants supplemented with different prophylactic iron doses did not differ in terms of growth and nutritional status. However, infants from the group with intermittent supplementation (group III) and from the group treated with a higher daily dose (group II) showed significant increase in weight/age and weight/length $z$ scores, respectively. Even though the iron doses markedly differed in terms of content and frequency, the groups with higher doses (group I and II) did not show differences regarding weight gain, length gain and anthropometrical indices (weight/age, length/age and weight/length) in comparison with the group who received lower doses (group III). According to these results, neither content nor frequency of prophylactic iron doses influenced the growth of non-anemic infants. 
Table 1 - Characteristics of participants at admission and daily nutrient intake during the supplementation period

\begin{tabular}{|c|c|c|c|c|}
\hline Characteristics & Group I $(n=39)$ & Group II $(n=36)$ & Group III $(n=39)$ & $\mathbf{p}$ \\
\hline Male sex, \% & $46.2 \%(18)$ & $55.6 \%(20)$ & $59.0 \%(23)$ & $0.502^{*}$ \\
\hline Age, months & $5.97 \pm 0.55$ & $5.82 \pm 0.45$ & $5.93 \pm 0.60$ & $0.464^{+}$ \\
\hline Capillary hemoglobin, g/dL & $12.1 \pm 0.9$ & $11.8 \pm 0.9$ & $12.2 \pm 0.9$ & $0.218^{+}$ \\
\hline Birth weight, $g$ & $3,273 \pm 349$ & $3,420 \pm 475$ & $3,227 \pm 386$ & $0.105^{+}$ \\
\hline Maternal age, years & $27.3 \pm 5.6$ & $27.7 \pm 5.2$ & $25.3 \pm 4.6$ & $0.106^{+}$ \\
\hline Per capita income, minimum wage & $0.42(0.27-0.76)$ & $0.36(0.27-0.50)$ & $0.33(0.21-0.44)$ & $0.181^{\ddagger}$ \\
\hline Maternal education, years & $8(4-11)$ & $8(5-10)$ & $7(5-11)$ & $0.977^{\ddagger}$ \\
\hline $\begin{array}{l}\text { Duration of exclusive breastfeeding, } \\
\text { days }\end{array}$ & $60(7-90)$ & $30(8-120)$ & $16(9-60)$ & $0.465^{+}$ \\
\hline $\begin{array}{l}\text { Duration of predominant breastfeeding, } \\
\text { days }\end{array}$ & $135(90-154)$ & $150(105-150)$ & $120(49-160)$ & $0.509^{\ddagger}$ \\
\hline Breastfeeding, $\%$ & $79.5 \%(31)$ & $80.6 \%(29)$ & $79.5 \%(31)$ & $0.991^{*}$ \\
\hline \multicolumn{5}{|l|}{ Nutrients } \\
\hline Energy (kcal) & $798.0(611.1-950.0)$ & $718.3(523.7-903.4)$ & $\begin{array}{c}835.2 \\
(583.8-1,070.3)\end{array}$ & $0.362^{\ddagger}$ \\
\hline Energy (kcal/kg weight) & $90.0(69.8-114.3)$ & $83.6(62.5-112.5)$ & $93.6(66.9-119.8)$ & $0.680^{\neq}$ \\
\hline Iron (mg) & $4.57(2.21-12.06)$ & $4.75(1.79-9.60)$ & $4.33(2.81-14.69)$ & $0.587^{ \pm}$ \\
\hline Iron density $(\mathrm{mg} / 1.000 \mathrm{kcal})$ & $5.24(3.81-10.95)$ & $5.02(3.08-10.88)$ & $5.45(3.91-13.25)$ & $0.539^{\neq}$ \\
\hline Bioavailable iron (mg) & $0.20(0.09-0.48)$ & $0.15(0.08-0.41)$ & $0.19(0.10-0.53)$ & $0.606^{\ddagger}$ \\
\hline Retinol (Eq/Ret) & $\begin{array}{c}596.0 \\
(388.7-1.064 .7)\end{array}$ & $470.7(33.7-792.0)$ & $483.9(329.3-639.7)$ & $0.144^{\ddagger}$ \\
\hline Calcium (mg) & $289.5(188.1-840.4)$ & $255.5(156.4-684.7)$ & $358.9(179.1-927.3)$ & $0.464^{\neq}$ \\
\hline
\end{tabular}

Values presented as percentages and corresponding number in brackets, mean \pm standard deviation, median with 25 th and 75 th percentiles in brackets.

* Chi-square test.

+ Analysis of variance.

‡ Kruskal-Wallis test.

Consistently with these results, other studies also did not find differences between the effects of intermittent and daily iron supplementation on the nutritional status of infants. ${ }^{23,24}$ However, a study with school-aged Thai children demonstrated that, after 16 weeks of supplementation, the group supplemented with a weekly dose of iron (60 mg/week) showed higher length gain comparatively to the group supplemented with a daily dose (60 mg/day). ${ }^{25}$

There are few studies about the benefits and risks of daily iron supplementation in non-anemic, non-iron-deficient infants. In Indonesia, a study with non-iron-deficient infants revealed, after 4 months, that the group supplemented with $3 \mathrm{mg}$ of iron/ $\mathrm{kg} / \mathrm{day}$ had a lower weight gain than the placebo group. ${ }^{14}$ In this Indonesian study, a higher iron dose (therapeutic dose) was administered to children without iron deficiency. Such practice is rarely verified in universal iron supplementation programs, which normally use lower doses (prophylactic doses). In a study with breast-fed infants supplemented with prophylactic doses of iron $(1 \mathrm{mg} / \mathrm{kg} /$ day), distinct results were obtained in evaluated populations. In Sweden, supplementation between the fourth and the ninth months of age was related to a lower length gain and to a lower head circumference. In a study performed in Honduras, where children presented poor iron nutrition, supplementation between the fourth and sixth months had a negative effect only on non-anemic infants. ${ }^{15}$ The authors warned against the risk of adverse effects on health in the long run caused by daily iron supplementation in infants younger than 6 months, due to the immature regulation of iron metabolism.

With regard to the groups assessed in the present study, group I, which received the same iron dose ( $1 \mathrm{mg} / \mathrm{kg} / \mathrm{day}$ ) as in the previously mentioned work, ${ }^{15}$ showed similar gains in weight and length in comparison with the other groups. A 
Table 2 - Measurements and anthropometric indices of groups before and after supplementation

\begin{tabular}{|c|c|c|c|c|}
\hline & Group I & Group II & Group III & p* \\
\hline \multicolumn{5}{|l|}{ Weight, kg } \\
\hline Initial & $7.709 \pm 0.896^{a}$ & $7.570 \pm 0.881^{a}$ & $7.823 \pm 1.231^{\mathrm{a}}$ & 0.563 \\
\hline Final & $8.910 \pm 1.079^{b}$ & $8.837 \pm 1.023^{b}$ & $9.202 \pm 1.491^{\mathrm{b}}$ & 0.389 \\
\hline Increment & $1.201 \pm 0.503$ & $1.267 \pm 0.372$ & $1.379 \pm 0.524$ & 0.254 \\
\hline $\mathrm{p}^{+}$ & 0.000 & 0.000 & 0.000 & \\
\hline \multicolumn{5}{|l|}{ Length, $\mathrm{cm}$} \\
\hline Initial & $66.72 \pm 2.32^{a}$ & $66.85 \pm 2.07^{a}$ & $67.17 \pm 3.26^{a}$ & 0.738 \\
\hline Final & $71.88 \pm 2.52^{\mathrm{b}}$ & $72.07 \pm 2.36^{\mathrm{b}}$ & $72.28 \pm 3.45^{b}$ & 0.333 \\
\hline Increment & $5.15 \pm 1.14$ & $5.22 \pm 1.01$ & $5.61 \pm 1.09$ & 0.134 \\
\hline $\mathrm{p}^{+}$ & 0.000 & 0.000 & 0.000 & \\
\hline \multicolumn{5}{|c|}{ Weight/age, z score } \\
\hline Initial & $0.110 \pm 0.878$ & $-0.064 \pm 1.051$ & $0.124 \pm 1.253^{\mathrm{a}}$ & 0.704 \\
\hline Final & $0.124 \pm 0.967$ & $0.027 \pm 1.097$ & $0.290 \pm 1.358^{\mathrm{b}}$ & 0.606 \\
\hline Increment & $0.015 \pm 0.487$ & $0.092 \pm 0.324$ & $0.167 \pm 0.481$ & 0.319 \\
\hline $\mathrm{p}^{+}$ & 0.854 & 0.107 & 0.035 & \\
\hline \multicolumn{5}{|c|}{ Length/age, z score } \\
\hline Initial & $0.087 \pm 0.898$ & $0.172 \pm 0.915$ & $0.208 \pm 1.358$ & 0.881 \\
\hline Final & $-0.038 \pm 0.939$ & $0.083 \pm 0.983$ & $0.283 \pm 1.308$ & 0.427 \\
\hline Increment & $-0.131 \pm 0.484$ & $-0.092 \pm 0.391$ & $0.072 \pm 0.497$ & 0.127 \\
\hline $\mathrm{p}^{+}$ & 0.117 & 0.173 & 0.349 & \\
\hline \multicolumn{5}{|c|}{ Weight/length, z score } \\
\hline Initial & $0.174 \pm 0.898$ & $-0.136 \pm 1.142^{a}$ & $0.112 \pm 1.181$ & 0.428 \\
\hline Final & $0.234 \pm 1.067$ & $0.039 \pm 1.073^{b}$ & $0.260 \pm 1.317$ & 0.669 \\
\hline Increment & $0.062 \pm 0.535$ & $0.169 \pm 0.153$ & $0.151 \pm 0.632$ & 0.671 \\
\hline $\mathrm{p}^{+}$ & 0.487 & 0.046 & 0.153 & \\
\hline
\end{tabular}

Values expressed as mean \pm standard deviation.

Different letters in columns and on lines indicate statistical differences $(p<0.05)-$ paired $^{t}$ test.

Groups did not differ in terms of anthropometric variables $(p>0.05)$ - analysis of variance.

* Analysis of variance.

+ Paired t test.

recent systematic review concluded that iron supplementation did not affect the weight and length of infants. ${ }^{10}$ In addition, the study showed no association between initial hemoglobin levels and the effects of supplementation on growth.

It is estimated that the prevalence of iron deficiency anemia increases as the prevalence of nutritional anemias increases. ${ }^{1}$ Thus, considering the high prevalence of anemia $(36.6 \%)$ verified in the screening phase of the study, a great number of the selected non-anemic infants supposedly had some iron deficiency before the intervention. In addition, it is unlikely that the ingestion of prophylactic iron doses has caused impaired the growth or the nutritional status of the evaluated infants, because during the supplementation period there were increases in weight/age and weight/length of the general population. Length/age did not show significant changes after the supplementation.

There is no evidence about which mechanisms could explain how iron supplementation can interfere in growth. However, indirect effects might be involved. The benefits of iron supplementation on growth could be justified by increased appetite and consequently higher food intake, ${ }^{13}$ or even by strengthening of the immune system, with positive consequences such as a reduction in the incidence of morbidity. ${ }^{3}$ On the other hand, some probable negative effects of iron supplementation are mentioned in the literature, such as competitive inhibition of other nutrients by iron; for example, zinc, which has a direct effect on growth processes. The authors of 
Table 3 - Occurrence and duration of morbidity during supplementation

\begin{tabular}{|c|c|c|c|c|}
\hline $\begin{array}{l}\text { Morbidity in the past } 15 \\
\text { days, \% }\end{array}$ & Group I (n = 39) & Group II $(n=36)$ & Group III (n = 38) & $\mathbf{p}$ \\
\hline 1st evaluation & $47.4 \%(18)$ & $41.7 \%(15)$ & $36.8 \%(14)$ & $0.648^{+}$ \\
\hline 2nd evaluation & $56.4 \%(22)$ & $69.4 \%(25)$ & $60.5 \%(23)$ & $0.497^{+}$ \\
\hline 3rd evaluation & $56.4 \%(22)$ & $61.1 \%(22)$ & $52.6 \%(20)$ & $0.762^{+}$ \\
\hline 4th evaluation & $71.8 \%(28)$ & $63.9 \%(23)$ & $65.8 \%(25)$ & $0.746^{+}$ \\
\hline Diarrhea, \% & $28.2 \%(11)$ & $33.3 \%(12)$ & $31.6 \%(12)$ & $0.887^{+}$ \\
\hline Duration of diarrhea, days & $5.0(3.0-7.0)$ & $5.0(3.2-7.0)$ & $7.0(5.5-14.0)$ & $0.084^{\ddagger}$ \\
\hline Fever, \% & $51.3 \%(20)$ & $77.8 \%(28)$ & $57.9 \%(22)$ & $0.050^{+}$ \\
\hline Duration of fever, days & $2.0(1.0-3.2)$ & $2.0(1.0-2.8)$ & $2.0(1.0-2.0)$ & $0.820^{\ddagger}$ \\
\hline Cough, \% & $71.8 \%(28)$ & $80.6 \%(29)$ & $84.6 \%(32)$ & $0.391^{+}$ \\
\hline Duration of cough, days & $7.0(5.0-11.8)$ & $7.0(5.0-13.5)$ & $7.3(5.0-11.5)$ & $0.958^{\neq}$ \\
\hline Coryza or nasal congestion, $\%$ & $82.1 \%(32)$ & $86.1 \%(31)$ & $89.5 \%(34)$ & $0.645^{+}$ \\
\hline $\begin{array}{l}\text { Duration of coryza or nasal } \\
\text { congestion, days }\end{array}$ & $6.7(4.5-9.0)$ & $8.0(4.3-11.2)$ & $6.9(5.0-10.0)$ & $0.611^{\neq}$ \\
\hline Wheezing, \% & $59.0 \%(23)$ & $61.1 \%(22)$ & $71.1 \%(27)$ & $0.504^{+}$ \\
\hline Duration of wheezing, days & $7.0(5.2-11.0)$ & $9.7(5.0-15.0)$ & $7.0(5.0-10.1)$ & $0.403^{\neq}$ \\
\hline
\end{tabular}

Values expressed as percentages and corresponding numbers in brackets, median with 25th and 75th percentiles in brackets.

* Percentage of children with some morbidity episode during the experiment.

${ }^{+}$Chi-square test.

* Kruskal-Wallis test.

a recent review claimed that there is a lack of evidence linking iron supplementation to reduced zinc serum levels. ${ }^{26}$ Another hypothesis is that iron could enhance vulnerability to infections and, consequently, impair growth. The findings about this association are controversial. ${ }^{16,17}$ There is also the hypothesis that excess body iron, due to its pro-oxidant characteristic, could stimulate the formation of free radicals, damaging several metabolic processes, including growth. 9,15

During supplementation, the groups did not differ in terms of morbidity and duration of diarrhea, fever, cough, coryza or nasal congestion and wheezing. On the other hand, monthly evaluations showed great morbidity in this population: more than half of the infants presented some kind of morbidity. Also, symptoms of respiratory infections, such as cough, coryza or nasal congestion and wheezing, were reported.

According to Oppenheimer, ${ }^{16}$ there is no evidence that iron supplementation is associated with increased morbidity in non-endemic areas of malaria. However, in endemic areas, therapeutic iron supplementation can increase the risk of infectious diseases. Gera \& Sachdev ${ }^{17}$ concluded that iron supplementation did not affect the general incidence of infections, but that it increased the risks for diarrhea. The authors asserted that such fact would not have an impact on public health, because of the little difference in the incidence of diarrheal episodes. In another study, prophylactic iron supplementation showed reduced risk of diarrhea in anemic individuals but increased the risk in non-anemic ones. ${ }^{15}$ The existence of many confounding factors, which affect both the immunity and the iron nutritional status of populations, can hinder the interpretation of results of intervention studies.

Generally, infants showed improvement in weight/age and weight/length indices during supplementation in the present study. The general monthly mean weight gain (337.7 \pm 127.6 g) was above the World Health Organization recommendation, which is around $313 \mathrm{~g}$ (2006). ${ }^{22}$ As to length/age, nutritional status was maintained after supplementation. Monthly mean length gain $(1.33 \pm 0.27 \mathrm{~cm})$ was somewhat below recommendation $(1.46 \mathrm{~cm})$.

A study involving Indonesian, Peruvian, Vietnamese and South African infants showed that iron and/or micronutrient supplementation did not control growth deficits in the first year of life. ${ }^{27}$ The benefits of iron supplementation on children's growth are likely to be more evident in populations with severe nutritional problems. Nutritional status of anemic populations also seems to benefit from iron supplementation. ${ }^{28}$

With regard to dietary intake, $61.4 \%(n=70)$ of the infants showed adequate energy intake compared to the estimated energy requirement. ${ }^{29}$ However, considering that $80 \%$ were being breast-fed, it is believed that daily variations in breast milk intake may have guaranteed more adequate energy ingestion. It should be pointed out that the amount of 
breast milk ingested was not directly assessed, but rather estimated, based on a predictive formula. ${ }^{20}$ Probably, this procedure caused the total intake of breast milk to be underestimated.

Certainly, a methodological limitation of the present study is the absence of a placebo group. This prevents us from drawing accurate conclusions about the effect of iron supplementation on the nutritional status of non-anemic children. It is still worthy mentioning that the detection of effects on growth and on nutritional status generally requires a greater sample size than the one used in this study. However, this is one of the few studies that compared the effect of different prophylactic iron doses on infants in the first year of life, as well as the critical period concerning iron requirements and physical development.

The conclusion is that different prophylactic iron doses did not show a differential effect on the growth and nutritional status of non-anemic infants. Besides, the growth of infants who received daily iron supplements ( 1 or $2 \mathrm{mg} / \mathrm{kg} / \mathrm{day}$ ) was similar to that of infants given intermittent iron doses ( 25 $\mathrm{mg} /$ week). Other studies are necessary in order to confirm these results and to investigate the effect of prophylactic iron supplementation on anemic and non-anemic children.

\section{Acknowledgements}

We would like to thank Nutrition undergraduates of Universidade Federal de Viçosa for their help with the fieldwork.

\section{References}

1. World Health Organization (WHO). Iron deficiency anaemia. Assessment, prevention, and control. A guide for programme managers. Geneva:UNICEF/UNU/WHO, 2001.

2. Grantham-McGregor S, Ani C. A review of studies on the effect of iron deficiency on cognitive development in children. J Nutr. 2001;131:S649-66.

3. Chwang L, Soemantri AG, Pollitt E. Iron supplementation and physical growth of rural Indonesian children. Am J Clin Nutr. 1988;47:496-501.

4. Judisch JM, Naiman JL, Oski FA. Fallacy of the fat iron-deficient child. Pediatrics. 1966;37:987-90.

5. United Nations Children 's Fund, United Nations University, World Health Organization, Micronutrient Initiative (UNICEF/UNU/ WHO/MI). Preventing iron deficiency in women and children: background and consensus on key technical issues and resources for advocacy, planning, and implementing national programmes. New York: International Nutrition Foundation/Micronutrient Initiative; 1999.

6. American Academy of Pediatrics. Iron supplementation for infants. Pediatrics. 1976;58:765-8.
7. Sociedade Brasileira de Pediatria. Preconização da profilaxia de ferro em lactentes. Atualidades SBP. 1995;4:12.

8. Brasil. Ministério da Saúde.Manual Operacional do Programa Nacional de Suplementação de Ferro/Ministério da Saúde, Secretaria de Atenção à Saúde, Departamento de Atenção Básica. Brasília: Ministério da Saúde; 2005.

9. Iannotti LL, Tielsch JM, Black MM, Black RE. Iron supplementation in early childhood: health benefits and risks. Am J Clin Nutr. 2006;84:1261-76.

10. Sachdev H, Gera T, Nestel P. Effect of iron supplementation on physical growth in children: systematic review of randomised controlled trials. Public Health Nutr. 2006; 9:904-20.

11. Dijkhuizen MA, Wieringa FT, West CE, Martuti S, Muhilal. Effects of iron and zinc supplementation in Indonesian infants on micronutrient status and growth. J Nutr. 2001;131:2860-5.

12. Angeles IT, Schultink WJ, Matulessi P, Gross R, Sastroamidjojo S. Decreased rate of stunting among anemic Indonesian preschool children through iron supplementation. Am J Clin Nutr. 1993;58:339-42.

13. Lawless JW, Latham MC, Stephenson LS, Kinoti SN, Pertet AM. Iron supplementation improves appetite and growth in anemic Kenyan primary school children. J Nutr. 1994;124:645-54.

14. Idjradinata P, Watkins WE, Pollitt E. Adverse effect of iron supplementation on weight gain of iron replete young children. Lancet. 1994;343:1252-4.

15. Dewey KG, Domellöf M, Cohen RJ, Rivera L, Hernell O, Lönnerdal B. Iron supplementation affects growth and morbility of breast-fed infants: results of a randomized trial in Sweden and Honduras. J Nutr. 2002;132:3249-55.

16. Oppenheimer SI. Iron and its relation to immunity and infectious disease. J Nutr. 2001;131:S616-33.

17. Gera T, Sachdev HP. Effect of iron supplementation on incidence of infectious illness in children: systematic review. BMJ. 2002; 325:1142-4.

18. Bhandari N, Bahl R, Taneja S. Effect of micronutrient supplementation on linear growth of children. Br J Nutr. 2001;85 Suppl 2:S131-7.

19. World Health Organization (WHO). Indicators for assessing breast-feeding practices. WHO/CDC, 1992.

20. Drewett RF, Woolridge MW, Jackson DA, Imong SM, Mangklabruks A, Wongsawasdii $L$, et al. Relationships between nursing patterns, supplementary food intake and breast-milk intake in a rural Thai population. Early Hum Dev. 1989;20: 13-23.

21. Monsen ER, Hallberg L, Layrisse M, Hegsted DM, Cook JD, Mertz W, et al. Estimation of available dietary iron. Am J Clin Nutr. 1978;31:134-41.

22. World Health Organization (WHO). WHO child growth standards: length/height-for-age, weight-for-age, weight-for-length, weight-for-height and body mass index-for-age: methods and development. http://www.who.int/childgrowth/publications/ technical_report_pub/en/index.html. Access: 15/07/2007.

23. Soemantri AG, Hapsari DE, Susanto JC, Rohadi W, Tamam M, Irawan PW, et al. Daily and weekly iron supplementation and physical growth of school age Indonesian children. Southeast Asian J Trop Med Public Health. 1997;28 Suppl 2:69-74.

24. Thu BD, Schultink W, Dillon D, Gross R, Leswara ND, Khoi HH. Effect of daily and weekly micronutrient supplementation on micronutrient deficiencies and growth in young Vietnamese children. Am J Clin Nutr. 1999;69:80-6. 
25. Sungthong R, Mo-Suwan L, Chongsuvivatwong V, Geater AF. Once weekly is superior to daily iron supplementation on height gain but not on hematological improvement among schoolchildren in Thailand. J Nutr. 2002;132:418-22.

26. Fischer Walker C, Kordas K, Stoltzfus RJ, Black RE. Interactive effects of iron and zinc on biochemical and functional outcomes in supplementation trials. Am J Clin Nutr. 2005;82:5-12.

27. Smuts CM, Lombard CJ, Benade AJ, Dhansay MA, Berger J, Hop le $T$, et al. Efficacy of a foodlet-based multiple micronutrient supplement for preventing growth faltering, anemia, and micronutrient deficiency of infants: the four country IRIS trial pooled data analysis. J Nutr. 2005;135:631S-638S.

28. Lima AC, Lima MC, Guerra MQ, Romani SA, Eickmann SH, Lira PI. Impact of weekly treatment with ferrous sulfate on hemoglobin level, morbidity and nutritional status of anemic infants. J Pediatr (Rio J). 2006;82:452-7.
29. Institute of Medicine. Dietary reference intakes for energy, carbohydrate, fiber, fat, fatty acids, cholesterol, protein and amino acids. Washington, DC: National Academy Press, 2002.

Correspondence:

Danielle Góes da Silva

Núcleo de Nutrição

Centro de Ciências Biológicas e da Saúde

Universidade Federal de Sergipe

Cidade Universitária Prof. José Aloísio de Campos

Av. Marechal Rondon, s/no - Jardim Rosa Elze

CEP 49100-000 - São Cristovão, SE - Brazil

Tel.: + 55 (79) 2105.6662, +55 (79) 9900.8991

E-mail: daniellegoes@ufs.br 